\title{
О МИНЕРАЛЬНОМ СОСТАВЕ НИЖНЕОРДОВИКСКИХ ФОСФАТОНОСНЫХ И ПОДСТИЛАЮЩИХ ИХ ОТЛОЖЕНИИ В СЕВЕРНОЙ ЭСТОНИИ
}

Ордовикский разрез начинается, как известно, терригенными фосфатоносными отложениями пакерортского горизонта - т. н. оболовыми песчаниками, переходящими выше в граптолитовые аргиллиты (диктионемовые сланцы) и глауконитовые песчаники, а затем в преобладающие в разрезе карбонатные породы. Таким образом, фосфатоносные песчаники являются базальными для крупного цикла ордовикских отложений, которые начали формироваться после длительного континентального перерыва.

Литология оболовых песчаников, в частности распределение в них фосфатных компонентов, была предметом изучения геологов как при поиско-разведочных работах на фосфатное сырье, так и при его промышленном освоении. Минеральному же составу фосфатоносных отложений уделялось до сих пор мало внимания, хотя обломочные компоненты этой части разреза могут дать ценную информацию для выяснения вопросов об унаследованности минерального состава ордовикских отложений от более древних, в частности, кембрийских отложений, а также для уточнения некоторых аспектов палеогеографии бассейна. Чтобы восполнить этот пробел, авторами были обобщены по схеме Х. Вийдинга (1976) результаты количественного минералогического анализа 90 проб из 22 обнажений Северо-Эстонского глинта, выполненные в центральной лаборатории Управления геологии СМ ЭССР (аналитик Л. Валлисте) и в Институте геологии АН ЭССР. Х. Хейнсалу изучен типоморфный состав кварца в 25 пробах из пакерортского горизонта и подстилающей его тискреской свиты нижнего кембрия.

Минеральный состав изучался методом иммерсии во фракции 0,10,05 мм, составляющей в пакерортских фосфатоносных отложениях в среднем 10-40\% от обломочных терригенных зерен, а в тискреских алевролитах еще больше. В породах пакерортского горизонта преобладают наиболее устойчивые минералы. Аллотигенная часть легкой фракции почти полностью представлена обломочным кварцем. Калиевые полевые шпаты чаще присутствуют в количестве $1-4 \%$, реже в количестве $5-11 \%$ (лишь в 10\% проб). Глауконит и слюда встречаются единичными зернами. Содержание биогенного компонента (детрита брахиопод) обычно колеблется в пределах $3-10 \%$.

Тяжелые минералы (плотностью выше 2,89 г/ $\mathrm{cm}^{3}$ ) составляют от всей породы лишь десятые или даже сотые доли процента; выходы, превы- 


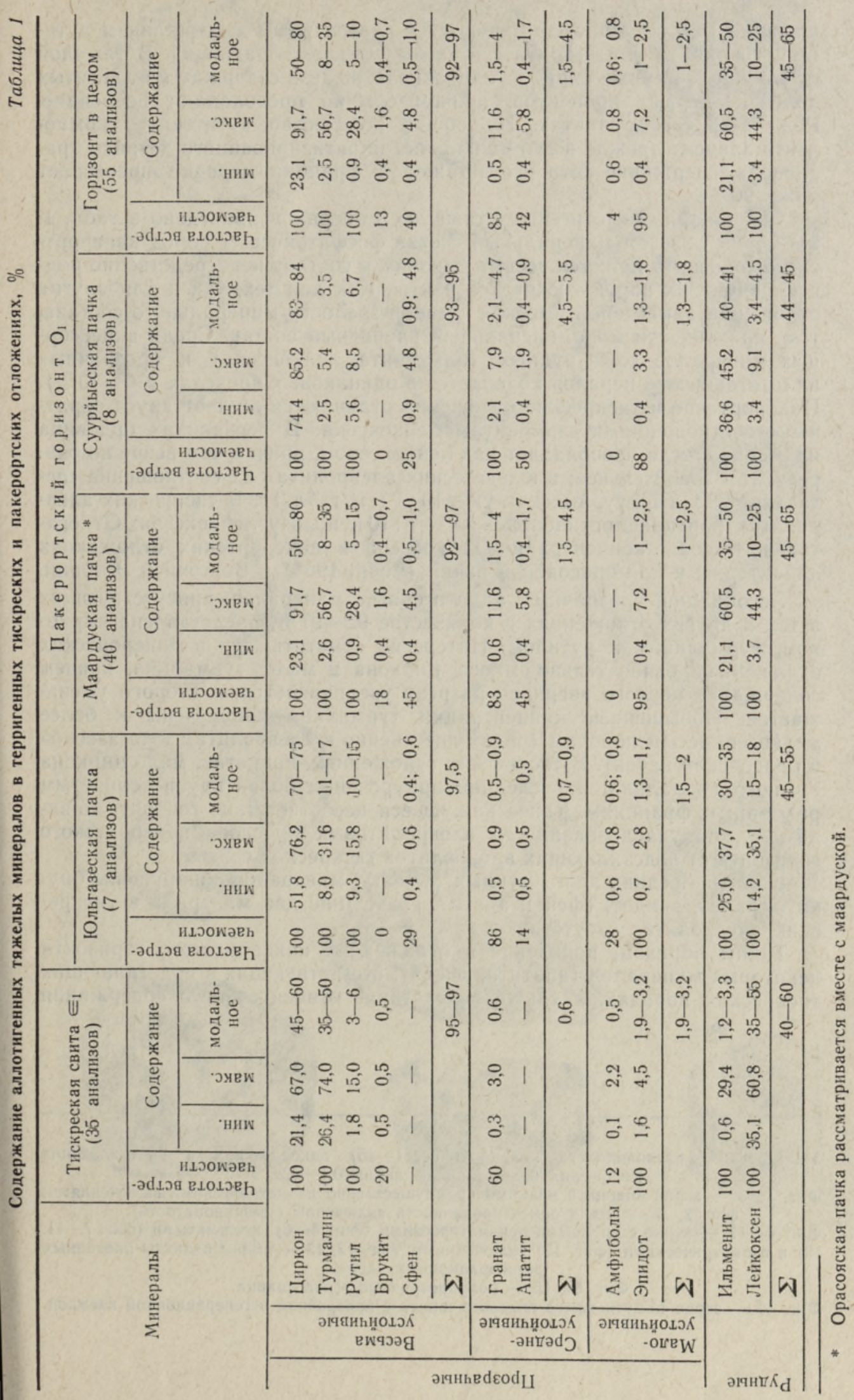


шающие $1 \%$, всегда ассоциируются с повышенным содержанием аутигенного пирита или детрита фосфатных створок брахиопод. В тяжелой фракции аутигенные пирит и гидроокислы железа содержатся от десятых долей до первых процентов, причем обычно преобладают последние. Реже встречается анатаз. Но общее количество аутигенного компонента зависит прежде всего от наличия пиритизированного детрита брахиопод, содержание которого в тяжелой фракции нередко превышает даже $90 \%$.

Содержание аллотигенных тяжелых минералов приведено в табл. 1. На первый взгляд минеральный состав фосфатоносных пород пакерортского горизонта кажется весьма близким к составу непосредственно подстилающих их пород тискреской свиты. Как для тех, так и для других отложений характерна высокая степень зрелости минерального состава, т. е. практически мономинеральный кварцевый состав. Среди акцессорных минералов доля рудных (ильменита, лейкоксена) и прозрачных аллотигенных минералов колеблется в одинаковых пределах $(30-70 \%)$. Пакерортские и тискреские отложения отличаются друг от друга обратными соотношениями ильменита и лейкоксена. В песчаниках ордовика ильменит всегда преобладает над лейкоксеном, причем чем выше по разрезу, тем значительнее: в юльгазеских алевролитах их соотношение составляет $2: 1$, а в суурйыеских уже $10: 1$ (см. табл. 1). В тискреских алевролитах картина противоположна $-1: 10$ в пользу лейкоксена. Относительно высокие концентрации лейкоксена в пакерортских отложениях характерны и для орасояской пачки (Loog, 1964) в Восточной Эстонии.

Ассоциация прозрачных аллотигенных минералов, присутствующих в тех и других отложениях в количестве $92-97 \%$, представлена цирконом, турмалином и рутилом. Интересно отметить, что в пакерортских отложениях относительно много циркона и мало турмалина, причем содержание первого вверх по разрезу увеличивается, а второго уменьшается. Повышенные концентрации турмалина приурочены к более мелкозернистым породам (преимущественно к алевролитам юльгазеской и орасояской пачек). В тискреских отложениях, напротив, мало циркона и много турмалина, и последний приурочен к более крупнозернистым размерным фракциям. Такое кажущееся несоответствие говорит, по-видимому, об унаследованности алевролитовых прослоев пакерортского горизонта от подстилающих алевролитов тискреской свиты.

Из более редких аллотигенных тяжелых минералов обнаружены брукит, гранат, эпидот, сфен и апатит. Последние два минерала в тискреских алевролитах отсутствуют.

Таким образом, появление в отложениях пакерортского горизонта некоторых минералов (апатита, сфена), отсутствующих в подстилающих тискреских породах, а также возрастание относительного содержания

Типоморфные разновидности кварца (фиг. 1-15) пакерортских и подстилающих тискреских отложений (фракция $0,1-0,25$ м.м).

Фиг. 1-3 - зерна кварца с мелкими преимущественно изометрическими включениями; фиг. 2,3 - видна ориентированность включений (трещиноватость).

Фиг. 4-13 - зерна с крупными прнзматическими (фиг. $4-6)$, игольчатыми (фиг. $7-11$, 13) и изометрическими (фиг. 12) включениями; фиг. 12, 13 - видны реликты окатанных регенерационных каемок.

Фиг. 14, 15 - полупрозрачные зерна кварца.

Фиг. 16 - зерно помутневшего полевого шпата с прозрачной регенерацнонной каемкой. 


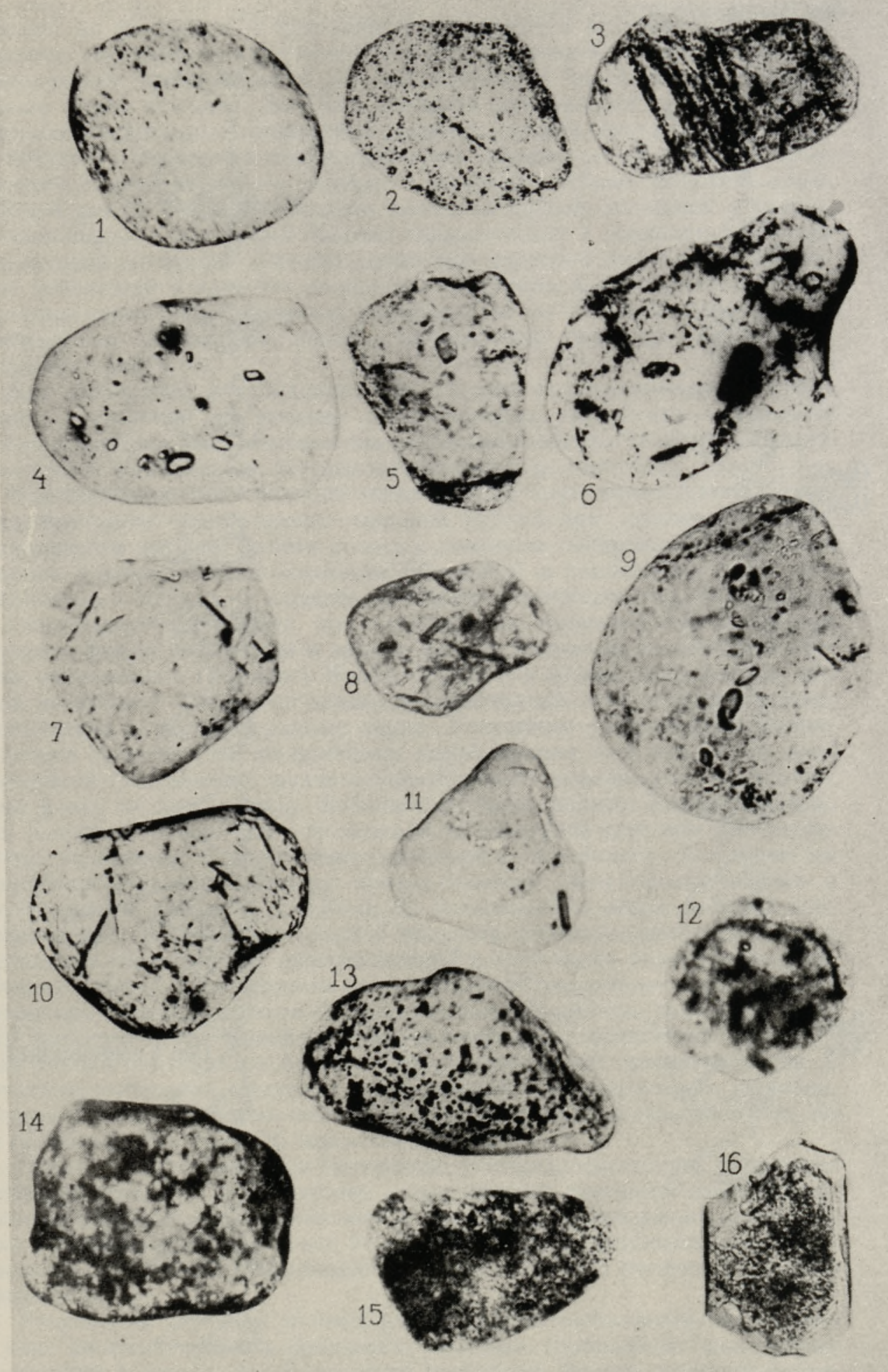




\section{Обн. Раннамыйза}

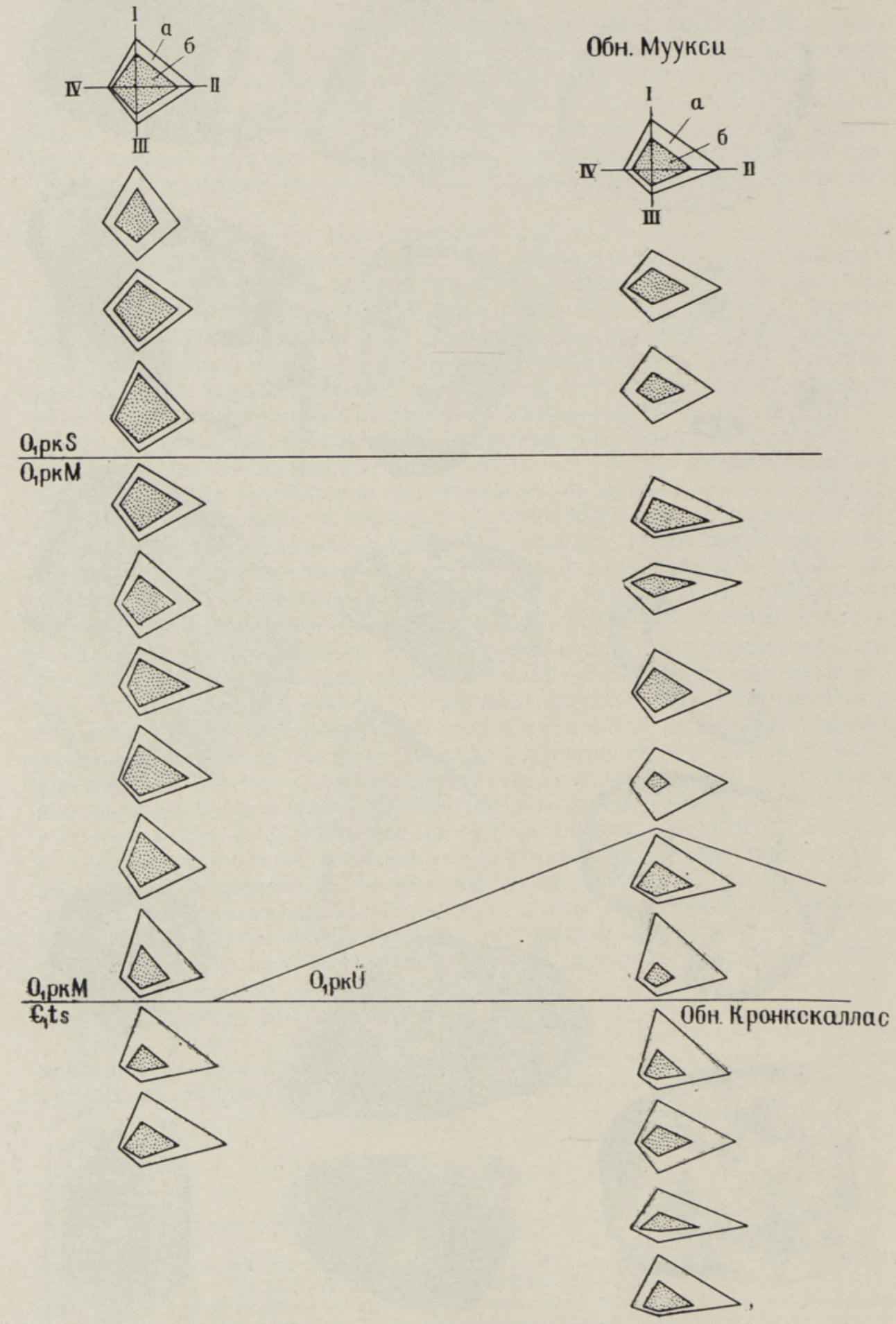

Типоморфный состав кварца, \%: I - зерна с изометрическими включениями, II зерна с призматнческими нли продолговатыми включениями, III - зерна с игольчатымн включениями, IV - полупрозрачные зерна кварца; $a-$ нормальное погасание, 6 - волннстое погасание. 
циркона по сравнению с турмалином и ильменита по сравнению с лейкоксеном позволяют предполагать лишь частичное переотложение в пакерортское время широко распространенных подстилающих терригенных пород кембрия. Высокая зрелость минерального состава пакерортских терригенных отложений говорит скорее всего о результате глубокого выветривания пород удаленной области сноса в течение длительного континентального периода в позднем кембрии. В новом, ордовикском цикле осадконакопления появился другой источник питания, поставляющий в обширный бассейн седиментации в основном песчаный обломочный материал. Однако полностью отрицать значение кембрийских отложений в качестве исходного материала для накопления пакерортских нельзя. По-видимому, размываемые на соседних территориях кембрийские отложения играли наибольшую роль при накоплении базальных слоев.

Для выяснения унаследованности состава рассматриваемых терригенных отложений от состава подстилающих тискреских отложений нижнего кембрия были изучены типоморфные особенности кварца из трех обнажений: Раннамыйза, Муукси и Кронкскаллас (рисунок).

Исследованию подвергались зерна кварца крупностью $0,1-0,25$ мм, предварительно обработанные царской водкой для удаления пленок гидроокислов железа. Работа велась с помощью поляризационного микроскопа в иммерсионной жидкости $(N=1,543)$ в проходящем свете при увеличении в 200 раз. В каждом препарате подсчитывалось 400 зерен.

Основными критериями при определении типоморфных признаков служили форма включений в зернах кварца, характер погасания и степень окатанности (Вийдинг, Конса, 1976). По форме учитывались три типа включений (изометрические, продолговатые или призматические, игольчатые) и полупрозрачные зерна. Указанные типоморфные разновидности выделяли не по принципу преобладания того или иного типа включений (что обычно трудно осуществимо из-за разных их размеров), а по факту их присутствия, предпочитая более редкие. Таким образом, при подсчете прежде всего принимали во внимание есть или нет игольчатые включения (соотношение размеров 1:4 и более). В случае их отсутствия учитывали наличие призматических (или продолговатых с соотношением размеров $1: 1,5-1: 4)$ включений, а вслед за ними изометрических. В результате такого подсчета отпадала необходимость в выделении типоморфных разновидностей с точечными включениями, поскольку наряду с последними использованное увеличение почти всегда позволяло обнаружить хотя бы одно мелкое игольчатое, призматическое или изометрическое включение. Зерна кварца без включений в изученных пробах практически отсутствуют. Преобладают изометрические и точечные включения жидкости и газа, а включения турмалина, циркона, рутила, биотита, полевых шпатов и других минералов присутствуют, но не преобладают в $30-40 \%$ зерен кварца.

Поскольку, кроме формы включений, учитывалось еще два вида погасания (нормальное и волнистое) и три степени окатанности (малоокатанные, полуокатанные и окатанные зерна), то общее число типоморфных разновидностей достигало 24. Дополнительно учитывали ориентированность включений (трещиноватые зерна) и зерна с регенерационными каемками.

Результаты изучения типоморфизма кварца изображены на рисунке в виде двойных лучевых диаграмм, которые отображают как форму включений в зернах, так и характер погасания. Третий основной критерий типоморфизма кварца - степень окатанности - оказался в данном случае менее информативным. Подавляющее большинство зерен (60- 
$84 \%$ ) характеризуется средней степенью окатанности. Малоокатанные зерна составляют от 7 до $33 \%$, а хорошо окатанные от 1 до $19 \%$. Последних заметно меньше в тискреских и юльгазеских отложениях $(0,5-5 \%)$ и больше в вышележащих маардуских и суурйыеских (в среднем 10$15 \%)$. Объясняется это прежде всего размерами зерен, которые в тискреских и юльгазеских отложениях близки к нижнему пределу изученной фракции 0,1-0,25 мм. Зерна такой крупности, по-видимому, меньше подвергаются окатыванию, поскольку меньше переносятся волочением по дну водоема. Зерна маардуских и суурйыеских пород, как более крупные в пределах этой фракцин, окатаны лучше.

Типоморфный состав кварца изученных пород по содержанию различных включений на первый взгляд кажется довольно однородным. Почти во всех пробах преобладают зерна с призматическими или продолговатыми включениями (рисунок). Второе (редко первое) место занимают зерна кварца, имеющие в своем составе только изометрические включения (фототаблица, фиг. 1,2 ). Полупрозрачные разновидности кварца и зерна с игольчатыми включениями обычно присутствуют в малом количестве.

При более детальном рассмотрении все же выявляются некоторые тенденции к изменению типоморфных признаков кварца по разрезу от тискреских отложений к пакерортским. Определенную направленность изменений по вертикальному разрезу показывают зерна кварца с игольчатыми и призматическими включениями, соотношение зерен с нормальным и волнистым погасанием и в некоторой степени зерна с ориентированными включениями (трещиноватые зерна).

Зерна с игольчатыми включениями (фототаблица, фиг. $7-11,13$ ), составляющие среди остальных выделенных типоморфных разновидностей $6-24 \%$, имеют явную тенденцию к увеличению их относительного количества снизу вверх (табл. 2), а зерна с призматическими (или просто продолговатыми) включениями (фототаблица, фиг. 4-6), составляющие $25-52 \%,-$ напротив, сверху вниз.

Характер погасания зерен кварца в тискреских и вышележащих пакерортских отложениях различен. В тискреских алевролитах всегда преобладают зерна с нормальным погасанием (рисунок), причем соотношение нормального и волнистого погасаний для них меняется от $1,1: 1$ до $2: 1$. В пакерортских отложениях это соотношение обратное - от $1: 1$ до 1:3, т. е. превалируют зерна с волнистым погасанием. Такая закономерность не прослеживается только в полупрозрачных зернах кварца (фототаблица, фиг. 14, 15), где преобладает, как правнло, волнистое погасание.

Следует отметить, что характерный для тискреских алевролитов

Таблица 2

Среднее содержание включений в кварце, \%

\begin{tabular}{|c|c|c|c|c|}
\hline \multirow[b]{2}{*}{$\begin{array}{l}\text { Пачка } \\
\text { (свита) }\end{array}$} & \multicolumn{3}{|c|}{ Включения } & \multirow[b]{2}{*}{$\begin{array}{c}\text { Полупрозрач- } \\
\text { ные зерна }\end{array}$} \\
\hline & $\begin{array}{l}\text { изометриче- } \\
\text { ские }\end{array}$ & $\begin{array}{c}\text { продолгова- } \\
\text { тые или } \\
\text { призматиче- } \\
\text { ские }\end{array}$ & игольчатые & \\
\hline $\begin{array}{l}\mathrm{O}_{1} \mathrm{pkS} \\
\mathrm{O}_{1} \mathrm{pkM} \\
\mathrm{O}_{1} \mathrm{pkU} \\
\in_{1} \mathrm{ts}\end{array}$ & $\begin{array}{l}28,1 \\
26,7 \\
34,0 \\
30,0\end{array}$ & $\begin{array}{l}34,0 \\
42,8 \\
43,5 \\
46,5\end{array}$ & $\begin{array}{r}19,9 \\
16,7 \\
10,0 \\
9,8\end{array}$ & $\begin{array}{l}18,0 \\
13,8 \\
12,5 \\
13,7\end{array}$ \\
\hline
\end{tabular}


признак - преобладание зерен кварца с нормальным погасанием - не меняется резко на границе кембрия - ордовика, а сохраняется и в самых низах ордовика, в алевролитах юльгазеской пачки и в нижнем «оболовом конгломерате». Выше по разрезу они уступают место разновидностям кварца с волнистым погасанием (рисунок). Сохранение нормального погасания кварца в базальных слоях пакерорта является выражением унаследованности их минерального состава от тискреских отложений.

В распределении по разрезу зерен кварца с ориентированным расположением мелких включений (трещиноватые зерна; фототаблица, фиг. 2,3 ) также обнаруживается некоторая закономерность: в тискреских и юльгазеских алевролитах их всегда не более $9-20 \%$, а в вышезалегающих маардуских и суурйыеских песчаниках уже $20-34 \%$. Увеличение количества трещиноватых зерен вверх по разрезу нижнеордовикских фосфатоносных отложений подмечено и в пакерортских отложениях Ленинградской области (Кулямин, Хазанович, 1971). Такая тенденция, указывающая на возрастающую роль метаморфизма исходных обломочных пород, хорошо согласуется с данными по волнистому погасанию кварца. Наиболее высокие содержания трещиноватых зерен $(27-32 \%)$ связаны с прослоями «оболового конгломерата»в маардуской и с богатыми детритом прослоями в суурйыеской пачках, отличающихся, как правило, от остальных пакерортских отложений более крупным гранулометрическим составом.

Регенерационные каемки, вернее окатанные реликты их (фототаблица, фиг. 12,13$)$, встречаются на кварце редко $(1-2 \%)$. В пакерортских отложениях они, в сущности, нмеют аллотигенный характер. Зато у зерен полевых шпатов очень часто видна аутигенная, очень прозрачная, с четко выраженными кристаллографическими гранями и без следов окатывания каемка регенерации (фототаблица, фиг. 16).

Сходство некоторых типоморфных признаков кварца в самых нижних частях пакерортского горизонта (юльгазеская пачка, «оболовый конгломерат») и в верхней части тискреской свиты позволяет говорить об унаследованности минерального состава, несмотря на то что значительно более крупный гранулометрический состав «оболового конгломерата» вроде бы противоречит этому. О появлении нового источника сноса свидетельствуют, во-первых, тот факт, что выше по разрезу в пакерортском горизонте увеличивается доля кварца с волнистым погасанием и трещиноватых зерен и, во-вторых, изменение количественных соотношений аллотигенных тяжелых минералов.

Таким образом, сравнительный минералогический анализ обломочных, в частности акцессорных, минералов вместе с изучением распределения типоморфных разновидностей кварца по разрезу позволяет рассматривать раннеордовикский этап терригенного осадконакопления в Эстонии как новый и по составу отложений независимый от подстилающих кембрийских обломочных пород. Следы унаследованности минерального состава проявляются лишь в самых низах фосфатоносных отложений.

\section{ЛИТ Р РА Т У Р А}

В ийдинг Х. А. 1976. Об интерпретации данных минералогического анализа. В сб.; Методика и интерпретация результатов минералогических и геохимических
исследований. Вильнюс, с. $53-59$.

В и йдин г Х. А., К о н а М. 1976. Учет данных по типоморфным разновидностям минералов терригенных отложений. В сб.: Методика и интерпретация результа- 
К ул я м и н Л. Н., Х а з а н о в и ч К. К. 1971. Обломочный кварц из кембро-ордовикской песчаной толщи Ленинградской области. Литология и полезные ископаемые, № $4,88-94$.

Loog, A. 1964. Pakerordi lademe litostratigraafilisest liigestusest avamusel. VII Eesti loodusuurijate päeva ettekannete teesid. Tartu, lk. 82-84.

\section{PŌHJA-EESTI ALAMORDOVIITSIUMI FOSFORIITISISALDAVATE SETENDITE JA NENDE LAMAMI MINERAALSEST KOOSTISEST}

Artikkel käsitleb pakerordi lademe fosforiitisisaldavate liivakivide ja lamavate tiskre kihistu aleuroliitide mineraalse koostise võrdleva uurimise tulemusi. On analüüsitud jämealeuriitse fraktsiooni kergeid ja raskeid mineraale ning kvartsiterakeste $(0,1-$ $0,25 \mathrm{~mm}$ ) tüpomorf́sete erimite jaotust vertikaalprofiilis. Kerge fraktsiooni mineraalselt koostiselt nimetatud kivimid oluliselt ei erine: mōlemates leidub valitseva kvartsi kõrval tavaliselt vaid $1-4 \%$ kaaliumpäevakive, vähem vilku ja glaukoniiti. Raske fraktsiooni $\left(>2,89 \mathrm{~g} / \mathrm{cm}^{3}\right)$ suuremad $(>1 \%)$ sisaldused on seotud autigeense püriidi vỗi rauahüdroksiidide, pakerordi lademes aga peamiselt fosfaatse, kohati püritiseerunud detriidi esinemisega. Kuigi valitsevate raskete allotigeensete mineraalide assotsiatsioonide poolest on iseloomustatavad terrigeensed setendid sarnased, erinevad nad selgelt mõningate mineraalide, eriti leukokseeni, ilmeniidi, tsirkooni ja turmaliini vahekorra poolest (tab. 1). Erinevused ilmnevad ka kvartsi tüpomorfsete erimite hulkades (joon. 1).

Raskete mineraalide suhtelise hulga muutuste sujuv iseloom, samuti nagu kvartsiterakeste tüpomorfsete erimite muutuste pidevus kambriumi ja ordoviitsiumi piirikihtides lubab kõnelda kambriumi settematerjali pärandamisest vaid ordoviitsiumi fosforiitisisaldavate liivakivide kõige alumiste kihtide piires. Ordoviitsiumi terrigeensete setete kuhjumisega algas basseini uus arenguetapp, mida iseloomustab setete suurele mineraloogilisele küpsusele vaatamata mineraalse koostise teatud eripära.

\section{ON THE MINERAL COMPOSITION OF NORTH ESTONIAN LOWER ORDOVICIAN PHOSPHORITE-CONTAINING DEPOSITS AND UNDERLYING STRATA}

The article is concerned with the results of a comparative study of the mineral composition of phosphorite-containing sandstones in the Pakerort Stage and in the aleurites of the underlying Tiskre Member. The distribution of the light and heavy minerals of the coarse-grained fraction of aleurites and the typomorphic varieties of quartz grains $(0.1-0.25 \mathrm{~mm})$ in the vertical profile has been subjected to analyses. The above-mentioned rocks do not reveal any substantial difference in the composition of minerals of the light fraction: as a rule, both contain, next to predominating quartz, only 1-4 per cent potassium feldspars and to a lesser extent mica and glauconite. The greater contents $(>1 \%)$ of the heavy fraction $\left(>2.89 \mathrm{~g} / \mathrm{cm}^{3}\right)$ are connected with the presence of authigenous pyrite or ferrum hydroxides, and in the Pakerort Stage - with phosphatic and pyritized detrite. Though the examined terrigenous deposits are similar in the association of the prevalent heavy allotigenous minerals, they differ clearly in the content of some minerals, and particularly in the ratio of leucoxene, ilmenite, zircon and tourmaline (Table 1). Differences also occur in the amounts of typomorphic varieties of quartz (Fig. 1).

The gradual changes of the relative amounts of heavy minerals as well as the continuous changes of the typomorphic varieties of quartz grains in the border layers of the Cambrian and Ordovician permit us to speak of the inherited nature of the Cambrian sedimentary material only within the lowermost strata of Ordovician phosphorite-containing sandstones. With the accumulation of Ordovician terrigenous sediments, a new stage in the development of the basin was initiated, which is characterized by certain peculiarities of the mineralogical composition of the deposits, despite their mineralogical maturity. 